\title{
Analysis of the Ecological Consciousness Cultivation of Contemporary College Students
}

\author{
Ying Ji \\ Oxbirdge College, Kunming University of Science and Technology, Kunming, Yunnan, 650000
}

Keywords: College Students; Ecological Consciousness, Cultivation

\begin{abstract}
In order to conform to the progress of the times and meet the actual needs of all-round talent development, the key position of ecological consciousness becomes more and more significant. However, under the influence of various factors, some of the ecological awareness of college students there is a very serious lack of a direct result of its difficult to take responsibility for the construction of ecological society. Therefore, higher education should enhance the ecological awareness of college students. This paper focuses on the cultivation of ecological consciousness of contemporary college students, and tries to provide a reference for future related work.
\end{abstract}

\section{Introduction}

All education needs to shape and cultivate specialized talents, and then to ensure their own survival and progress, and promote social and cultural harmony. In the course of carrying out the model of ecological civilization education, the key position of college students' ecological consciousness is more important. But in fact, many college students' ecological consciousness is weak, and the historical responsibility that needs to bear is contrary to each other. Therefore, the cultivation of ecological consciousness of contemporary college students has become an urgent problem to be solved in domestic higher education, and it is the key theory and practice research direction.

\section{Analysis of the Main Factors of Contemporary College Students' Ecological Consciousness}

The ecological civilization consciousness of college students is very weak, which is usually reflected in the value and right of attaching importance to their own, not paying attention to the value and the right of the natural law; paying attention to the current ecology of the sensibility of the ecology. Demand, do not attach importance to the value of spiritual civilization needs; attention to their own ecological civilization freedom and rights, do not attach importance to others and the overall social ecological civilization freedom and power.

Social factors are the objective factors of the weak ecological consciousness of contemporary college students, which are mainly embodied in: first, the role of social transformation. In the current period, the society mainly developed from the original homogeneity to the heterogeneous direction. At this stage, its diversification model directly led to the development of values in the direction of diversification. Some groups and individuals in the interests of the premise, the overall social interests become gradually thin, and even difficult to clear. Therefore, social groups and individuals are difficult to produce the ecological consciousness needed to maintain the long-term progress of society; secondly, the adverse effects of China's market economy. China's economy is in the early stages of socialism, people's livelihood strategy will pay more attention to economic development needs, will be selected in line with the current national conditions of the market economy model, but the market interests of the core of the highest profit goals and values will be a waste of resources Energy and Harm the ecological environment of the problem, the negative impact of the problem will certainly contemporary college students have a negative impact on the ecological environment awareness; Third, the role of the West not the correct concept. Since the outbreak of the industrial revolution so far, Western countries, the concept of ecological awareness 
has always been the main human center. The idea sums up the connection of man and nature into the use of the connection with being used, manipulated, and manipulated. To take selfish ideas to occupy and control the natural ecology, and to control others and social civilization, a direct result of the natural ecology has become a human and human rights and interests of each other and the influx of victims, and thus continue to meet their material needs, evolved into people on the material Unscheduled quest for thinking. In addition, capital-controlled science and technology and ethics become the auxiliary tool of thinking, and its results on the one hand lead to the risk of human and natural contact rupture, on the other hand affect the social relations between people, Physical and mental have produced a very serious negative impact, and ultimately the long-term development of the world's economy and human survival have an impact, continue to consume the development of civilization with the value and resources. It is not difficult to find that, in the minds of human capital, in the process of thinking and practice, we continue to deepen the tension between mankind and nature. With the development of the world history of the world history, the humanistic core of the thinking mode has entered the country, directly on the contemporary college students ecological civilization awareness has formed a very serious adverse effect.

This aspect is mainly the subjective factor of contemporary college students' ecological environment consciousness, which is usually reflected in the deviation from the core concept of college students. With the increasingly prominent core consciousness of contemporary people and the extravagant extravagance of perceptual material life, each person's core rights and utilitarian thinking have been greatly improved, and more and more attention has been paid to the existence of their own interests aspect. Therefore, it is very easy for contemporary college students to pay more attention to their own material rights and internal balance, but it is difficult to consider the relationship between man and nature from the aspects of the overall ecological environment and future generations. Then the contemporary college students ecological environment awareness of the deviation or defects difficult to avoid.

\section{The Higher Education Function on the Ecological Awareness of Contemporary College Students}

In the current period, the ecological consciousness of college students is very thin, can not meet the social needs of the ecological environment, but also difficult to assume the responsibility of ecological civilization construction. Therefore, the domestic higher education needs to bear the responsibility of cultivating students' awareness of ecological environment. Because education is to promote the long-term development of society and enhance people eliminate the ecological environment of the core part. Education can make a better attitude to change, in the cultivation of contemporary college students ecological environment awareness, moral thinking and long-term development of several aspects of the concept has a very critical role. Can cultivate college students to participate in the relevant decision-making values and attitudes, enhance professional and technical, standardize the specific behavior.

The way of understanding the connection between man and nature usually consists of two categories, namely, the theory of opposition and the idea of unity. Among them, the concept of opposition is not correct, it also contains: eco-centrism and anthropocentrism two ideas. The theory of ecological center puts forward the concept of perception, its own value and "goodness" which people do not understand, and need to regard nature as the main body in the process of human and natural binary opposition, and put the rights of nature in the first place. However, because of its efforts to veto the value of modern economy and technology, and strive to use this concept to hinder the social and economic progress and technological revolution, thereby eliminating the ecological and environmental impact, to ecological society. On the one hand, it embodies the characteristics of non-historical ideas and mysticism in theory and it is impossible to get reasonable proof results. In addition, due to the weak core of the concept of humanism and the embodiment of the value of human destiny and the concept of sustainable development contrary to the same as in real life can not be effectively implemented. And this view corresponds to each other is said before the concept of human center. It is not difficult to find, whether it is the concept of human center, or the key to 
the ecological center, in the concept and practice, can not meet the harmonious needs of man and nature, can not eliminate the ecological and environmental problems, can not be found with a clear and reasonable ecological environment awareness and cultural thinking. So, these two keys are not correct.

From the perspective of philosophical thinking, leading to the source of this situation is the subject of contemporary issues. People are influenced by the idea of nature, and the cognitive ideas that people and nature are associated with each other. Leading to people in the process of learning people and nature linked to each other, to a large extent by the important influence of contemporary ideas, will be degraded to not subject to contemporary Marx thought up. The opposing situation of the binary opposition concept is fundamentally caused by the abstraction between man and nature. To eliminate such antagonism, it is necessary to scientifically and rationally analyze the philosophical thought that causes the opposition. It can be found that its historical responsibility is mainly realized by the practice of Marx's practice. Based on the philosophy of such philosophy, the connection between man and nature is mainly the harmony of practice as a mediator. First, the human can not be separated from the natural existence alone, the integrity of human nature and the improvement of human nature are dependent on the balance of nature; Second, the nature of the existence of their own, harmony and unity of nature rely mainly on human science applications and practice. In addition, the essence of the connection between man and nature is the social connection between people and people who practice as intermediaries. It also affects the ecological problems and the essence of ecological and environmental awareness. If contemporary college students can reasonably and correctly grasp the relationship between man and nature, they must have a positive effect on the emergence and practice of their own ecological environment consciousness.

Based on the dialectical connection between man and nature proposed by Marx, the ecological and environmental problems are embodied in the social connection between people and nature as the intermediary. As a prerequisite, it is from the social and cultural values to analyze the concept of humanism among the human center, and its people and the natural contact with each other to break the ecological problems to sort out. From the theory and practice of analysis and research, it is precisely because the capital of the private system as a prerequisite and people unfairly linked to each other material, and thus caused a variety of natural resources in the natural energy control and marketing, resulting in an ecological environment unfair (That is, between the ecological rights and obligations unfair), and then caused the capitalist system and the ecological environment between the fierce confrontation. If you want to eliminate the confrontation, you need to effectively eliminate the natural environment of the capitalist ideology. The promotion of the overall social progress is the fairness as the main body of the socialist system to replace. On the one hand, reflects the concept of human center can not continue to guide human values of natural activities, on the other hand reflects the re-construction of ecological concepts is to eliminate the current ecological problems of the main way. Therefore, higher education wants to enhance the ecological environment consciousness of contemporary college students, we must uphold the core values of the socialist system, reflect on and abolish the concept of centralism and ecology, and promote the contemporary students to have reasonable and correct ecological environment consciousness. Which belongs to a class not only contains the human dimension, but also contains the ecological dimension. On the one hand reflects the objective needs of the contemporary socialist system, on the other hand reflects the essence of the socialist concept and the future direction of development. It will be Marx's "focus on the liberation of man's natural liberation" as the core values of the ecological environment. And to guide the ecological awareness of contemporary college students to make their own ecological interests and the overall social and ecological rights and interests of scientific coordination, and ecological efforts and obligations between each other's ecological needs and the ultimate value of the ecological needs of each other, human survival And the natural coexistence of mutual contact between the coordination. Especially in the process of social connection practice, which covers the fairness of the ecological environment and the social justice thought as the core content, to promote the harmony and harmony between the people and the society and the society. 
Ecological consciousness belongs to a kind of value idea, its core value is to use the influence to reform people's sense of value, and then regulate people's behavior, improve people's consciousness, and finally realize their own values and significance of reflection and perception. In other words, the ecological environment consciousness is still the face of human life, it is not only the ideological aspects of thinking, but also with practical guidance, faith and practice are its characteristics, it is a concrete reflection of human ecological character and Practice. According to the basic concept of people-oriented in the reasonable development concept, the ecological needs of mankind and the ecological character of human beings have been perfected, and the ecological consciousness has always been the driving force and core consciousness. The ecological character referred to in this paper is a kind of main character, because the ecological environment consciousness must be rational and autonomous people to achieve, you need to control the freedom of consciousness, to ensure that external laws into human consciousness Sexual concept, and ultimately to eliminate the human center view of the adverse effects. Therefore, it is an important way to cultivate the ecological consciousness of contemporary college students to educate the ecological environment consciousness of contemporary college students and to enhance their own ecological virtues. Adhering to the socialist system values and human consciousness to integrate with each other, it is precisely to clarify the ecological environment awareness and practice to provide guidance, and bring a positive impact of the way, but also to save the natural and self-spiritual level of ideological enlightenment and awakening. Unless this is the case, we can effectively establish the ecological view of contemporary college students, enhance the sense of responsibility and justice, enhance and standardize the autonomy of ecological behavior of contemporary college students, and ensure the all-round development of college students in the process of harmony between man and nature and ultimately meet the individual "good".

\section{Conclusion}

To sum up, college students are the core forces of future social modernization, and their ecological consciousness has a very important impact on the overall society. However, the ecological consciousness of contemporary college students is still relatively weak, simply can not assume the responsibility of the construction of socialist ecological civilization. Therefore, it is necessary to cultivate the ecological environment consciousness of college students with the help of higher education, make clear the importance of ecological protection, standardize their own behavior, learn the relevant ecological protection technology, cultivate the consciousness of ecological environment protection, and finally make the sustainable development of our country.

\section{References}

[1] Wang Meng. Contemporary college students lack of ecological civilization awareness and training path [J]. Journal of Changchun Normal University, 2014, 33 (7): 128-130.

[2] Yin Xiaocheng. Contemporary college students ecological civilization awareness training [J]. Education, 2016 (11): 63-63.

[3] Zhang Qinqin. Contemporary college students ecological value of the path to develop [J]. Theory, 2016 (2): 249-250.

[4] Gong Changrui. College students ecological civilization values education focus and path analysis [J]. Theory, 2015 (9): 149-151.

[5] Chen Aihua. College students ecological civilization values education focus and path [J]. Yangtze River Series, 2016 (22): 215-215.

[6] Ming Zou. College students ecological civilization values cultivation path analysis [J]., 2016 (7): 68-69. 